\title{
Migraine In Systemic Lupus Erythematosus in Rheumatological outpatients unit
}

\author{
Ameer Shaker ${ }^{*}$, Akram Mohammed Al-Mahdawi ${ }^{* \star}$, Hayder Adnan Fawzi ${ }^{\star * *}$
}

\begin{abstract}
Background: Migraine is common in systemic lupus erythematosus.It is a significant source of patient disability.

Objective: To determine the rate of migraine in patients with systemic lupus erythematosus, to assess migraine type, severity, and the association between migraine and patient's characteristics.

Type of the study: Cross-sectional study.

Methods: 100 subjected were recruited and divided into two groups; fifty patients with the diagnosis of systemic lupus erythematosus were recruited from the Rheumatologic department of medicine, and another 50 normal subjects, then complete medical and drugs history were taken from them.

Results: Fifty patients completed the questionnaire. Thirty percent of systemic lupus erythematosus patients and $12 \%$ of normal subjects had migraine. Of the patients with migraine $80 \%, 13.3 \%$ and $6.7 \%$ met criteria for migraine without aura, migraine with aura and retinal migraine respectively. The moderately severe migraine was commonly observed (53.3\%). There were significant associations between migraine and systemic lupus
\end{abstract}

erythematosus patients who have Raynaud's phenomenon, and cardiolipin antibodies.There were no statistically significant associations between migraine, systemic lupus erythematosus duration and patient's age,sex, and anti-dsDNA.

Conclusions: $A$ high rate of migraine in patients with systemic lupus erythematosus. Migraine associated with Raynaud's phenomenon, and cardiolipin antibodies.

Key words:SLE, migraine, antiphospholipidantibodies, anticardiolipin antibodies.

\section{Al-Kindy College Medical Journal 2017: Vol. 13 No.1 Page: 51-55}

MD, FICMS, Department of neurology, Baghdad teaching hospital

${ }^{* *}$ CABM, FRCP, MRCP, college of medicine/ university of Baghdad

*** Pharm, RPh, Department of clinical pharmacy, Baghdad teaching hospital

Received 15 $5^{\text {th }}$ Feb 2017, accepted in final 30 March 2017 Corresponding to : Ameer Shaker. E-mail: ali.ne75@yahoo.com,, mobile : 07704592052
$\mathrm{M}$ igraine is a familial benign disorder characterized by periodic, commonly unilateral alternating in site but could be bilateral; often pulsatile may be associated with nausea, vomiting, photophobia and phonophobia $(1,2,3)$. Migraine is a highly prevalent headache disorder that has a substantial impact on the individual, society, and the family. The prevalence of migraine is high; and is highest in women, migraine attacks occur in up to 17 percent of women and 6 percent of men each year ${ }^{(4,5)}$. Migraine is most common in those aged 30 to 39 , where prevalence in men and women reaches 7 and 24 percent, respectively ${ }^{(5)}$. Migraine is thus about three times more common in women than men. Migraine also tends to run in families. Migraine without aura is the most common type, accounting for approximately 80 percent of cases ${ }^{(5)}$. Because of comorbidity, once a diagnosis of migraine has been established, clinicians should have a heightened index of suspicion for epilepsy, stroke, and psychiatric disorders.

Systemic lupus erythematosus (SLE) is a chronic, occasionally life threatening, multisystem disorder. Patients suffer from a wide array of symptoms and have a variable prognosis that depends upon the severity and type of organ involvement. Due to the uncertain course, effective treatment requires ongoing patientdoctorcommunication to correctly interpret laboratory tests, alleviate symptoms,prevent and treat relapses, and lessen side effects related to drug therapy theprevalence of SLE was one case per 1867 of the population, one per 1127 of thetotal female population and for women aged between 10 and 49 years it was oneper $616^{(6)}$. Central nervous system manifestations of SLE are highly diverseand often have major prognostic consequences. The incidence of CNSmanifestations attributable to SLE is not entirely clear and variable (44). ${ }^{(7)}$

This divergence has several reasons, one being differences of opinion concerning the syndromes that constitute the neurology and psychiatry of SLE, whether or not a syndrome is directly attributed to SLE, may have consequences for therapeutic strategies, Neurologic and psychiatric symptoms occur in 10 to 80 percent of patients either prior to the diagnosis of systemic lupus erythematosus (SLE), or during the course of their illness. ${ }^{(8)}$ The proposed mechanisms include vascular occlusion due to vasculopathy; vasculitis; leukoaggregation or thrombosis and antibody-mediated neuronal cell injury or dysfunctions. ${ }^{(9)}$ 
The neuropsychiatric SLE includes neurological syndromes of the central, peripheral and autonomic nervous system and psychiatric disorders in which other causes have been excluded. These manifestations may occur as a single or multiple events that might be important in diagnosis. ${ }^{(10)}$ It has not been possible to determine a specific cause for the high prevalence of headache in SLE patients. Some of the proposed theories until now include: autoantibodies production, microangiopathic,intrathecal production of proinflammatory cytokines, atherosclerosis, SLE central nervous system (CNS)-activity and use of several drugs, such as non-steroid-anti-inflammatory (NSAIDS)drugs or prednisone. ${ }^{(11)}$ On the other hand, some authors propose that there is no specific cause ofheadache in SLE, and that psychosocial factors and the presence of a chronicdisease may be responsible for this high prevalence. $^{(12)}$

Methods :

An observational case control study conducted on 50 patients with SLE who were seen atthe Rheumatology Unit, Department of Medicine andin Neurological Department inBaghdad Teaching Hospital from October 2009 to October 2010.The diagnosis of SLE was made by a rheumatologist using the criteriadeveloped by the
American College of Rheumatology. (13) 50 healthy individuals were randomly selected and were not taking any medications, written consentient were taken from all patient to participate in this study, the diagnosis of migraine made bythe International Headache Society (IHS) diagnostic criteria for migraine. ${ }^{(14)}$ Statistical Package for Social Sciences-Version 17 (SPSS v.17) used for data input and analysis. Pearson Chi square (test for Independence) and Fisher Exacttest used for verifying the association (relationship) between discrete variables asappropriate. The significance of difference between two independent continuousvariables was tested with t-test (t-test of two independent variables) when theywere normally distributed and with MannWhitney test when they are not normallydistributed.

\section{Results:}

Fifty patients with SLE, 43 females (86\%) \& 7 males $(14 \%)$, their mean age $(35.6 \pm 12.0)$ years, and 50 healthy control group, 43 females (86\%) \& 7 males $(14 \%)$, their mean age was $(38.4 \pm 10.8)$ years were included in this study. Migraine was present in 15 SLE patients $(30 \%)$, and absent in 35 SLE patients $(70 \%)$, while it was present in $6(12 \%)$, healthy individuals and absent in 44 (88\%) and is statistically significant.

Table 1: demographic data

\begin{tabular}{|c|c|c|c|c|}
\hline Variables & & SLE patients (50) & Normal subjects (50) & $P$ value \\
\hline Age (ye & $a n \pm S D)$ & $35.6 \pm 12$ & $38.4 \pm 10.8$ & 0.223 \\
\hline Gender & Male & $7(14 \%)$ & $7(14 \%)$ & 1.00 \\
\hline & Female & $43(86 \%)$ & $43(86 \%)$ & \\
\hline
\end{tabular}

\begin{tabular}{|cllllll|}
\hline \multicolumn{2}{|l}{ Table 2: association between migraine and SLE } & & & & \\
\hline & & SLE & Control & OR & $95 \% \mathrm{Cl}$ & P value \\
\hline \multirow{2}{*}{ Migraine } & Present & $15(30 \%)$ & $6(12 \%)$ & 3.143 & $1.105-8.942$ & 0.032 \\
\cline { 2 - 5 } & Absent & $35(70 \%)$ & $44(88 \%)$ & & & \\
\hline Binary logistic regression & & & & & \\
\hline
\end{tabular}

\begin{tabular}{|c|c|c|c|c|}
\hline \multicolumn{2}{|l|}{ Variables } & SLE patients & Normal subjects & $P$ value \\
\hline \multirow[t]{3}{*}{ Type of migraine } & Common & $12(80 \%)$ & $5(83.3 \%)$ & \multirow[t]{3}{*}{0.5} \\
\hline & Classic & $2(13.3 \%)$ & $1(16.7)$ & \\
\hline & Retinal & $1(6.7 \%)$ & 0 & \\
\hline \multirow[t]{2}{*}{ Severity of migraine } & Moderate & $8(53.3 \%)$ & $2(33.3 \%)$ & \multirow[t]{2}{*}{0.635} \\
\hline & Severe & $7(36.7 \%)$ & $4(66.7 \%)$ & \\
\hline
\end{tabular}




\begin{tabular}{|c|c|c|c|c|c|}
\hline \multicolumn{2}{|l|}{ Variables } & \multicolumn{2}{|c|}{ Migraine } & \multirow[t]{2}{*}{$P$ value } & \multirow[t]{2}{*}{ OR } \\
\hline \multicolumn{2}{|l|}{ Continuous variables } & Present & Absent & & \\
\hline \multicolumn{2}{|l|}{ Age $\{$ years $\}$ (mean \pm SD) } & $26.6 \pm 8.3$ & $35.2 \pm 13.4$ & $0.716^{\mathrm{a}}$ & - \\
\hline \multicolumn{2}{|c|}{ SLE duration $\{$ years $\}$ mean \pm SD } & $3.6 \pm 3.2$ & $6.2 \pm 6.7$ & $0.195^{\mathrm{b}}$ & - \\
\hline \multicolumn{2}{|c|}{ Discrete variables } & No (\%) & No (\%) & & \\
\hline \multirow[t]{2}{*}{ Gender } & Male (7) & 0 & $7(100 \%)$ & \multirow[t]{2}{*}{$0.062^{\mathrm{d}}$} & \multirow[t]{2}{*}{ - } \\
\hline & Female (43) & $15(34.9 \%)$ & $28(65.1 \%)$ & & \\
\hline SLE disease activity & Active & $15(30 \%)$ & $35(70 \%)$ & - & - \\
\hline \multirow[t]{2}{*}{ Reynaud's phenomenon } & Present (14) & $8(57.1 \%)$ & $6(42.9 \%)$ & \multirow[t]{2}{*}{$0.009^{\mathrm{C}}$} & \multirow[t]{2}{*}{5.524} \\
\hline & Absent (36) & $7(19.4 \%)$ & $29(80.6 \%)$ & & \\
\hline \multirow[t]{2}{*}{ Anxiety/depression } & Present (28) & $11(39.3 \%)$ & $17(60.7 \%)$ & \multirow[t]{2}{*}{$0.106^{\mathrm{C}}$} & \multirow[t]{2}{*}{0.343} \\
\hline & Absent (22) & $4(18.2 \%)$ & $18(81.8 \%)$ & & \\
\hline \multirow[t]{2}{*}{ Anti-Ds DNA } & Positive (46) & $14(30.4 \%)$ & $32(69.6 \%)$ & \multirow[t]{2}{*}{$0.82^{\mathrm{d}}$} & \multirow[t]{2}{*}{0.762} \\
\hline & Negative (4) & $1(25 \%)$ & $3(75 \%)$ & & \\
\hline \multirow[t]{2}{*}{ Anti cardiolipin ab } & Positive (10) & $6(60)$ & $4(40)$ & \multirow[t]{2}{*}{$0.021^{c}$} & \multirow[t]{2}{*}{5.167} \\
\hline & Negative (40) & $9(32.5 \%)$ & $31(77.5 \%)$ & & \\
\hline
\end{tabular}

Discussion : In the present study we found significant association between migraine andSLE.The pathogenesis of migraine in SLE is not clearly understood but possibleexplanations are; there might be SLE central nervous system (CNS)-activity, use of severaldrugs, such as non-steroid-anti-inflammatory (NSAIDS) drugs orprednisone, or the antiphospholipid syndrome. ${ }^{(11)}$ There is no specific cause of headache in SLE, and that psychosocial factorsand the presence of a chronic disease may be responsible for this highprevalence. ${ }^{(12)}$

Up to the best of our knowledge this is the $1^{\text {st }}$ case control study investigatingmigrainous headache in Iraqi SLE patients. The main finding of the present study is the high frequency of headache in ourpatient with SLE. The prevalence of migraine in SLE varies greatly among severalpublished studies, mainly due to design problems or the criteria used to diagnoseheadache. Since the implementation of the IHS criteria ${ }^{(14)}$, it has been easier tostandardize the presence of this common feature in a more accurate manner.

In this study, the rate of migraine was $30 \%$,this finding agreed withprevious studies done by Weder-Cisneros ND, ${ }^{(15)}$ D A Whitelaw, ${ }^{(16)}$ Dimos.Mitsikostas ${ }^{(17)}$, but contrasted with other studies done by Isenberg DA ${ }^{(18)}$ and SannaG. ${ }^{(19)}$ in which the association was not significant; this can be explained by that itwas studied before the standard protocol for IHS headache criteria.Comparisonsare difficult, as some authors do not provide detail. Brey et al $^{(20)}$ does not commentfurther on the nature of the headaches experienced in his cohort, while others donot utilize the IHS criteria. ${ }^{(14)}$ A further complicating factor in interpreting data isthe absence of control groups in a number of studies. ${ }^{(21)}$ Given the widely reportedrates for various forms of headache these omissions make any interpretation of thefrequency of headaches difficult.
Using fifty SLE patients and a validated questionnaire based on IHS migrainecriteria, we identified migraine in $30 \%$ of patients with SLE. In the present studymigraine occurred in $(34.9 \%)$ females \& $(0 \%)$ males. These findings do notconform to the pattern described in the general adult literature. Estimates of theprevalence of IHS-defined migraine in the general adult population range from $12.9 \%$ to $17.6 \%$ for women, and $3.4 \%$ to $6.1 \%$ for men ${ }^{(4,5)}$. The prevalence of migraine in patients aged 16 to 40 years was $30.3 \%$ and inpatients aged 41 to 48 years the prevalence was $29.4 \%$. In the general adultpopulation, the prevalence of migraine increases among both men and women untilthe age of 40 years, and then declines ${ }^{(22)}$.The failure to find a similar agerelateddecline in the prevalence of migraine in patients with SLE suggests that migraine isan attribute of the underlying disease. Other explanation is that SLE is about ninetimes as common in women as in men, with a peak age of onset between 20-40years ${ }^{(23)}$. Lastly was the way in which the diagnosis of migraine was made, usingquestionnaires which raise the issues of ascertainments bias, validity of self-reporting and case definition.

In the present study migraine in SLE was severe in $(46.75 \%)$ and moderate in(53.3\%), while control group was severe in $(66.7 \%)$ and moderate in $(33.3 \%)$, whichwas not significant. This high percentage of less severe migraine inSLE patient might be explained by ingestion of non-steroidal and steroidal drugsthat ameliorate headache.

In this study we did observe significant associations between migraine andRaynaud phenomenon, Raynaud's phenomenon is common in SLE. The severity of Raynaud'sphenomenon did not correlate with the frequency and severity of classical orcommon migraine. It was considered that small-vessel disease might underliethe clinical phenomena of SLE, including 
Raynaud's disease, and contribute to thecerebrovascular mechanism causing migraine ${ }^{(24)}$.Despite the lack of correlation between exacerbation of lupus and Raynaud'sphenomenon in the present study it seems reasonable to suggest that any youngfemale patient with migraine and Raynaud's phenomenon should be further investigated to exclude SLE. This could mean that migraine in SLE could have avascular physiopathological mechanism among other different associatedmechanisms ${ }^{(12)}$. Nevertheless, another study had not found association betweenheadache and Raynaud's phenomenon in patients with SLE ${ }^{(25)}$. At present, it is notpossible to explain this discrepancy. This also applies to the conflicting findings onthe possible association between the ACA syndrome and headaches. These data arecomplicated in that some studies report on the association between aPLantibodies, ${ }^{(26-28)}$ while others report on the ACA syndrome. ${ }^{(29)} A$ recent studyfound an association between the ACA syndrome and headaches but not withmigraine. ${ }^{(30)}$ This discrepancy could be related to population or study designdifferences or to searching intensity considering that prevalence of Raynaud'sphenomenon varies with the observer's specific questioning of the patient.

Also anticadiolipin antibodies significantly associated with migraine,this finding agreed with another previous studies done by Weder-Cisneros $N^{(15)}$, but contrasted with the study done by A FernaÂndez-Nebro ${ }^{\left({ }^{(3)}\right)}$.These discrepanciesmight be due to the technique of measuring these antibodies (we measure thepositivity and not the titers) and may be the activity of SLE disease.

In present study the incidence of common migraine in present study wassignificantly increased in the lupus group. It has some acceptance with otherstudies as Bonnie I. Glanz study ${ }^{(31)}$, but in present study there is high percentage ofcommon type in comparison to classical migraine which may be due to the smallsample of our study in comparison to the Bonnie I study (440 SLE patient) whichmay decrease the detection level of classical type, but was comparable with AFernaÂndezNebrostudy.

The main limitation of our study the case control nature limiting conclusionsregarding cause and effect relationship between migraine and SLE, also the smallsample taken. Despite that our findings call attention to high frequency ofmigraine in SLE patients that need treatment and help in management of SLEpatient to decrease morbidity.Due to the fact that headache may occur due to drugs such as steroid, on steroidaldrugs, and choroquine we decided to include migrainous SLE and non migrainousSLE in comparison and we found no statistical deference regarding drugs use, sothe presence of migraine could not be explained by recent corticosteroid, NSAID, anti-malarial, or immunosuppressive medication use.

\section{References}

1. Allan H. Ropper,M.d, Robert H.Brown,D.phil.M.D Adam's and Victor's principle ofneurology,Eighth edition,ch 10,p146-155.

2. Stephen L.Hauser,Harrison's neurology in clinical medicine,ch 5,p57-66.

3. Nima Mowzoon,M.D,Kelly D.Flemming,M.D,Neurology board review,ch 18,p694-698.

4. TI - Migraine prevalence. A review of population-based studies.AU - Stewart WF; Shechter A; Rasmussen BKSO - Neurology 1994 Jun;44(6 Suppl 4):S17-23.

5. TI - Migraine prevalence, disease burden, and the need for preventive therapy.AU - Lipton RB; Bigal ME; Diamond M; Freitag F; Reed ML; Stewart WFSO - Neurology. 2007 Jan 30;68(5):343-9.

6. Al-Rawi Z, Al-Shaarbaf $\mathrm{H}$, Al-Raheem E, Khalifa

SJ.http://www.ncbi.nlm.nih.gov/pubmed/68715 84.

7. New therapies for SLE .Rheum.dis.North Am 2000 may;26(2):389-400.

8. Kaell AT, Lee BC, Lockshin MD, et al. The diversity of neurological events in systemic lupus erythematosus. Arch Neurol 1987; 43: 273-6.Rood MJ, Breedveld FC. The accuracy of diagnosing neuropsychiatric systemic lupus erythematosus in series of 49 hospitalized patients. Clin Exp Rheumatol 1999; 17: 55-61.

9. $\mathrm{TI}$ - CNS lupus: a study of 41 patients. AU Joseph FG; Lammie GA; Scolding NJ SO Neurology. 2007 Aug 14;69(7):644-54.

10. Boumpas DT, Austin HA, Fessler BJ, et al. Systemic lupus erythematosus: emerging concepts. part1: renal, neuropsychiatric, cardiovascular, pulmonary and hematologic disease. Ann Int Med 1995; 122: 940-50.

11. TI - The 1982 revised criteria for the classification of systemic lupus erythematosus. Tan EM; Cohen AS; Fries JF; Masi AT; McShane DJ; Rothfield NF; Schaller JG; Talal N; Winchester RJ- Arthritis Rheum 1982 Nov;25(11):1271-7.

12. Omdal R, Waterloo K, Koldingnes W, Husby $\mathrm{G}$, Mellgren S. Somatic and psychological features of headache in systemic lupus erythematosus. J Rheumatol 2001; 28:772-9.

13. Hochberg, MC. Updating the American College of Rheumatology Revised criteria for the classification of systemic lupus erythematosus. Arthritis Rheum 1997; 40:1725.

14. Headache Classification Subcommittee of the International Headache Society. The International Classification of Headache Disorders: 2nd edition. Cephalalgia 2004; 24 Suppl 1:9. 
15. Prevalence and factors associated with headache in patients with systemic lupus

16. D A Whitelaw, F Hugo, J J Spangenberg and R Rickman Headaches in patients with systemic lupus erythematosus: a comparative study. Lupus 2004; $13 ; 501$

17. A meta-analysis for headache in systemic lupus erythematosus: the evidence and the myth. Dimos D. Mitsikostas, Petros P. Skakis and Peter J. GoadsbyAthens Naval Brain (2004), 127, 1200-1209. 18. Annals of the Rheumatic Diseases, 1982, 41, 30-32 A study of migraine in systemic lupus erythematosus

19. Sanna G, Bertolaccini ML, Cuadrado MJ et al. Neuropsychiatric manifestations in systemic lupus erythematosus: prevalence and association with antiphospholipid antibodies. J Rheumatol 2003; 30: 985-992.

20. Brey RL, Holliday SL, Saklad AR et al. Neuropsychiatric syndromes inlupus. Neurology 2001; 58: 1214-1220.

21. Vazquez-Cruz J, Traboulssi H, Rodriquez- De la Serna $A$ et al. A prospective study of chronic or recurrent headache in systemic lupus erythematosus. Headache 1990; 30: 232- 235.

22. Stewart WF, Shechter A, Rasmussen BK. Migraine prevalence. A review of population based studies.Neurology.1994;44(suppl 4):S17-S23.

23. Chakravarty, EF, Bush, TM, Manzi, S, et al. Prevalence of adult systemic lupus erythematosus in California and Pennsylvania in 2000: obtaid using hospitalization data. Arthritis ta. Arthritis Rheum 2007: 56:2092.
24. Dalessio D J. In: Bronica J J, ed. Advances in Neurology.New York: Raven Press, 1974; 4: 395401.

25. Glanz BI, Venkatesan $\mathrm{A}$, Schur $\mathrm{PH}$, Lew RA, Khoshbin S.Prevalence of migraine in patients with systemic lupus erythematosus. Headache 2001; 41:285-9.

26. Omdal R, Waterloo K, Koldingsnes W, Husby $\mathrm{G}$, Mellgren SI. Somatic and psychological features of headache in systemic lupus erythematosus.

27. Markus HS, Hopkinson N. Migraine and headache in systemic lupus erythematosus andtheir relationship with antibodies against phospholipids. J Neurol 1992; 239: 39-42.

28. Sfikakis PP, Mitsikostas DD, Manoussakis MN, Foukanelli, Moutsopoulos HM.Headaches in systemic lupus erythematosus: a controlled study. $\mathrm{Br}$ J Rheumatol 1998; 37:300-303.

29. Lipton RB, Stewart WF. Epidemiology and comorbidity ofmigraine. In: Goadsby PJ,Silberstein S, editors. Headache.Boston: ButterworthHeinemann, 1997:75-95.

30. Fernández-Nebro A, Palacios Muñoz R, Abarca-Costalago M, De Haro-Liger M,RodríguezAndreu J, González-Santos P. Chronic or recurrent headache in patients with systemic lupus erythematosus; a case control study. Lupus 1999; 8:151-6.

31. Prevalence of Migraine in Patients With Systemic Lupus Erythematosus Bonnie I. Glanz, PhD; Aradhana Venkatesan, BA; Peter H. Schur, MD; Robert A. Lew, PhD;Shahram Khoshbin, MD. Headache 2001;41:285-289 